OPEN ACCESS

Edited by:

Aimin Shi,

Institute of Food Science and Technology, Chinese Academy of Agricultural Sciences (CAAS), China

Reviewed by:

Shuai Chen,

Wuhan University, China Marwan M. A. Rashed,

Suzhou University, China

*Correspondence:

Cen Zhang

cenzhang@zju.edu.cn

Liangru Wu

boteatree@163.com

Hui Zhang

hubert0513@zju.edu.cn

Specialty section: This article was submitted to Nutrition and Food Science Technology,

a section of the journa

Frontiers in Nutrition

Received: 24 September 2021 Accepted: 01 November 2021 Published: 01 December 2021

Citation:

$X i$ Y, Zhang A, Wang Z, Farooq S, Zhang C, Wu L and Zhang $H$ (2021)

Improved Oxidation Stability of

Camellia Oil-in-Water Emulsions

Stabilized by the Mixed Monolayer of

Soy Protein Isolate/Bamboo Shoot Protein Complexes.

Front. Nutr. 8:782212.

doi: 10.3389/fnut.2021.782212

\section{Improved Oxidation Stability of Camellia Oil-in-Water Emulsions Stabilized by the Mixed Monolayer of Soy Protein Isolate/Bamboo Shoot Protein Complexes}

\author{
Yuhang $X i^{1}$, Aiping Zhang ${ }^{1}$, Zhongjiang Wang ${ }^{2}$, Shahzad Farooq ${ }^{1}$, Cen Zhang ${ }^{3 *}$, \\ Liangru $\mathrm{Wu}^{4 *}$ and Hui Zhang ${ }^{1,5 *}$ \\ 1 Zhejiang Key Laboratory for Agro-Food Processing, College of Biosystems Engineering and Food Science, Zhejiang \\ University, Hangzhou, China, ${ }^{2}$ College of Food Science, Northeast Agricultural University, Harbin, China, ${ }^{3}$ Institute of Food \\ Science, Zhejiang Academy of Agricultural Sciences, Hangzhou, China, ${ }^{4}$ China National Bamboo Research Center, \\ Hangzhou, China, ${ }^{5}$ Ningbo Research Institute, Zhejiang University, Ningbo, China
}

The complex of soy protein isolate (SPI)/bamboo shoot protein concentrate (BPC) was developed to stabilize camellia oil-in-water $(\mathrm{O} / \mathrm{W})$ emulsions. The surface hydrophobicity of the BPC/SPI complex driven by hydrogen bonds and electrostatic attractions was improved. With the increasing ratio of BPC in the complex, a tighter network layer structure of the complex was formed due to the rearrangement of proteins, and the emulsions showed a progressive enhancement in the gel-like structures. At the SPI/BPC ratio of 2:1, the emulsions had smaller droplet size and lower creaming index of $230 \mathrm{~nm}$ and $30 \%$, and the emulsifying activity and stability indices of the emulsions were $803.72 \mathrm{~min}$ and $11.85 \mathrm{~g} / \mathrm{m}^{2}$, respectively, indicating a better emulsifying activity and stability of emulsions. Meanwhile, the emulsions stabilized by the complex at the ratio of 2:1 showed better storage and antioxidant stability. These findings are expected to develop the application of bamboo shoots in emulsion-based food products such as mayonnaise, salad dressings, and sauces.

Keywords: bamboo shoot protein, soy protein isolate, emulsion, complex, oxidation stability

\section{INTRODUCTION}

Bamboo is a giant perennial arborescent grass that belongs to the family Poaceae containing over 1,250 species under 75 genera in the world (1). The bamboo shoot is the expanded bud or meristematic tissue of bamboo plants that grow into a tall bamboo plant within 3-4 months. Wang et al. (2) sorted out the protein of dozens of bamboo shoots and found that the highest protein level of the fresh bamboo shoots from D. giganteus and Y. alpine reached up to 3.86 $\mathrm{g} / 100 \mathrm{~g}$ wb and $33.4 \mathrm{~g} / 100 \mathrm{~g} \mathrm{db}$, respectively. Sayanika et al. (3) qualitatively analyzed the protein composition of bamboo shoots and found that the bamboo shoot had great potential as a healthy protein source for human consumption. Wang and $\mathrm{Ng}(4)$ extracted an antifungal protein (namely designated dendrocin) with a molecular weight of $20 \mathrm{kDa}$ from the shoots of D. latiflora Munro, which showed a good inhibitory effect on mycelial growth. In addition, Liu et al. (5) evaluated antihypertensive and antihyperlipidemic effects of bamboo shoot angiotensin converting enzyme 
inhibitory peptide on high-fat-diet-induced rats, and found that the peptide showed improved antioxidant activity, which could serve as a latent inhibitor of angiotensin converting enzyme to prevent cardiovascular diseases.

Soy protein isolate (SPI) is a commercial soy protein product made from defatted soy flour by removing most of the nonprotein components (e.g., fats and carbohydrates), and the protein content on dry basis in SPI is required to be over $90 \%$. Owing to its amphiphilic characteristics and high surface hydrophobicity, SPI could serve as an excellent emulsifier to improve the emulsion stability (6). Liu and Tang (7) reported that the nanoparticle aggregates of soy proteins were obtained by heat treatments at $95^{\circ} \mathrm{C}$ for $15 \mathrm{~min}$, which could form an effective pickering-like stabilizer for decreasing droplet size and increasing emulsion stability. Additionally, the addition of SPI could affect the rheology of emulsions, and then led to structural and functional changes, which may provide useful information for designing the emulsion-based food products such as mayonnaise, salad dressings, and sauces. Benetti et al. (8) produced the SPI microgel particles by ultrasound treatments and high pressure to modify the microstructure and rheological properties of the soybean oil-in-water (O/W) emulsions. Moreover, recent study showed that $\beta$-conglycinin and glycinin from SPI possessed good antimicrobial and antioxidant properties, which could improve the antioxidant activity of emulsions (9).

Protein-protein complexes can be formed by electrostatic attractive forces to improve emulsion stability. Compared with the emulsion stabilized by single protein, coadsorption of proteins at the oil-water interface could increase the viscosity and enhance the emulsion/foam stabilities. Wei et al. (10) prepared the emulsions stabilized by ovotransferrin-lysozyme complex through electrostatic interactions, and found that the emulsions had a decreased droplet size and displayed excellent stability during long-term storage. Zhang et al. (11) reported that the SPI/WPI complex could form an adsorption layer around the oil droplets, resulting in the improvement of emulsion stability.

The aim of this study was to probe the effects of the associative interactions between bamboo shoot protein concentrate (BPC) and SPI in the interfacial monolayer on physiochemical and rheological characteristics of the camelia $\mathrm{O} / \mathrm{W}$ emulsions, which was expected to develop BPC as an additive to the emulsion-based food products. To that purpose, contact angle measurements, and Fourier transform infrared (FTIR) were used to characterize the physical properties of the SPI/BPC complex particles, respectively. Moreover, the droplet size and interfacial tension (IFT) of the emulsions were measured, and emulsifying activity index (EAI), emulsion stability index (ESI), and creaming index (CI) were used to evaluate the emulsion stability. In addition, rheological measurements were performed to study the viscoelastic properties and apparent viscosity. The peroxide value (POV) and thiobarbituric acid-reactive substances (TBARS) were measured to explore the antioxidant of the prepared emulsions. In addition, the microstructure of emulsion droplets was investigated by transmission electron microscope (TEM).

\section{MATERIALS AND METHODS}

\section{Materials}

Soy protein isolated was purchased from Beijing OKA Biotechnology Co., Ltd. (Beijing, China). Camellia oil was bought from a local supermarket. Bamboo was provided by China National Bamboo Research Center. All the other chemicals were analytical grade.

\section{Extraction of BPC}

Bamboo shoot protein concentrate was extracted from bamboo shoot following a previous method with some modifications (12). Briefly, the bamboo shoots were mixed with MilliQ water at 1:10 (w/v) and the $\mathrm{pH}$ was adjusted to 8.0 using $0.1 \mathrm{M} \mathrm{NaOH}$ solution. Subsequently, the mixture was constantly stirred in a water bath at $45^{\circ} \mathrm{C}$ for $2 \mathrm{~h}$ and then filtered with 80 -mesh sieves. After centrifugation at $8,000 \mathrm{rpm}$ for $25 \mathrm{~min}$ at $4^{\circ} \mathrm{C}$, the supernatants were collected, and the precipitates were redissolved for centrifuge again. Then, BPC was obtained by spray drying and stored in a refrigerator at $-20^{\circ} \mathrm{C}$ for further analysis.

\section{Preparation of SPI/BPC Complex and Emulsions}

The SPI was dissolved in MilliQ water at a concentration of $4 \mathrm{wt} \%$. BPC was added to the SPI solution with mass ratios of $0: 1,1: 4,2: 4,3: 4$, and $4: 4$ (wt/wt), respectively. To prepare SPI/BPC complexes, a certain amount of camelia oil $(10 \% \mathrm{v} / \mathrm{v})$ was added into the solution of SPI/BPC with the aqueous phase by continuously stirring, followed by the $\mathrm{pH}$ adjustment to 8.0 using $0.1 \mathrm{M} \mathrm{NaOH}$ solution. The mixture was further homogenized using a high-speed homogenizer (IKA T25 digital ULTRATURRAX®, Germany) at 15,000 rpm for $3 \mathrm{~min}$. Afterward, the emulsions were prepared by high-pressure homogenization (Nano DeBEE30, BEE International, USA) at 25,000 psi for $5 \mathrm{~min}$ at $25^{\circ} \mathrm{C}$.

\section{Three-Phase Contact Angle Measurements}

The three-phase contact angle was measured on an OCA 20 contact angle meter (Data Physics Co. Ltd., Germany). Prior to measurement, the SPI/BPC complexes were pressed to the films with a thickness of about $2 \mathrm{~mm}$. A syringe was used to transfer 3.5 $\mu l$ of the solutions onto the surface, where the solutions were kept for $15 \mathrm{~min}$. The contact angle was calculated by the SCA software.

\section{FTIR Spectroscopy}

The infrared spectra of the particles were recorded on an FTIR instrument (Nicolet iS50, Thermo Fisher Scientific, China). The spectra were scanned with the absorbance mode of $4 \mathrm{~cm}^{-1}$ in the wavenumber range of 4,000-400 $\mathrm{cm}^{-1}$. All tests were conducted with air as the background.

The secondary structure of SPI and BPC was quantitatively determined by the analysis of the amide I region (1,700-1,600 $\mathrm{cm}^{-1}$ ) in the FTIR spectra. The contents of $\alpha$-helix, $\beta$-sheet, $\beta$ turn, and random coil components were calculated using Peakfit 4.12 software (13). 


\section{Droplet Size of Emulsions}

The droplet size or diameter of the emulsions stabilized by SPI/BPC complex was measured by dynamic light scattering according to the method of Chantrapornchai et al. (14) with slight modification. Samples were diluted 1,000 times by the MilliQ water, and then the droplet size of the emulsions was measured on a Zetasizer Nano-ZS90 (Malvern Instruments, Worcestershire, UK). The refractive index of water and camellia oil were 1.33 and 1.462, respectively. All measurements were carried out at $25^{\circ} \mathrm{C}$.

\section{Zeta Potential Measurement}

The zeta potential of SPI/BPC emulsions was measured by the Zetasizer Nano-ZS90 (Malvern Instruments, Worcestershire, UK) at $25^{\circ} \mathrm{C}$. Each sample was measured three times.

\section{Transmission Electron Microscope}

The morphology characterization of emulsion droplets was performed using the TEM (Tecnai G2 Spirit, Thermo FEI, Czech Republic) at an accelerating voltage of $120 \mathrm{kV}$ with the negative staining method (15). The samples $(0.4 \mathrm{mg} / \mathrm{ml})$ were added to a copper grid stained with phosphotungstic acid $(1 \% \mathrm{w} / \mathrm{v})$. The excess stain was removed, and the copper grids were dried at room temperature.

\section{IFT Measurements}

The IFT of the emulsions was measured on a tensiometer (OCA 20, Data Physics Co. Ltd., Germany) with the pendant drop method. The droplet of distilled emulsion was suspended on the tip of a syringe (22 gauge, I-quip), and then the pictures of the droplet were captured by a video camera. The IFT values were calculated by Young-Laplace equation (16).

$$
\gamma\left(\frac{1}{R_{1}}+\frac{1}{R_{2}}\right)=\Delta P(2-1)
$$

where $R_{1}$ and $R_{2}$ are the principal radii of curvature, $\gamma$ is the liquid surface tension coefficient, $\Delta P$ is the Laplace pressure across the interface.

\section{Emulsion Stability \\ Emulsifying Properties}

About $100 \mu \mathrm{l}$ of each emulsion sample was diluted with $5 \mathrm{ml}$ of $0.1 \%(\mathrm{w} / \mathrm{v})$ sodium dodecyl sulfate (SDS) solution and shaken rapidly. The absorbance was then measured at $500 \mathrm{~nm}$.

Emulsifying activity index $\left(\mathrm{m}^{2} / \mathrm{g}\right)$ and ESI $(\mathrm{min})$ were calculated using Equations (2-2) and Equations (2-3), suggested by Pearce and Kinsella (17):

$$
\begin{gathered}
E A I=2 \times 2.303 \times \frac{A_{0} \times d}{10000 \times \Phi \times C}(2-2) \\
E S I=\frac{A_{0}}{A_{0}-A_{10}} \times\left(T_{10}-T_{0}\right)
\end{gathered}
$$

where $C$ is the protein concentration $(\mathrm{g} / \mathrm{mL}), \Phi$ is the volume of the oil fraction $(\mathrm{v} / \mathrm{v})$ of the created emulsion $(\Phi=0.1), d$ is the dilution factor $(d=500), A_{0}$ and $A_{10}$ represent the absorbance at the beginning and after $10 \mathrm{~min}$, respectively.

\section{Cl Measurements}

Creaming index was calculated by a reported method (18). The freshly prepared emulsions were transferred into the same bottles and stored for 7 days at $25^{\circ} \mathrm{C}$. CI was measured at $24 \mathrm{~h}$ intervals and calculated as follows:

$$
C I=\frac{H_{S}}{H_{t}} \quad(2-4)
$$

where $H_{\mathrm{t}}$ is the total height of the emulsion, and $H_{\mathrm{s}}$ is the height of the creaming layer at the top.

\section{Rheological Properties}

A strain sweep test was performed to determine the linear viscoelastic region from 0.01 to $100 \%$ at $1 \mathrm{~Hz}$. The storage modulus $\left(G^{\prime}\right)$ and loss modulus $\left(G^{\prime \prime}\right)$ of sample were measured by frequency sweeping from 0.1 to $100 \mathrm{~Hz}$ at a constant stain of $1 \%(19)$.

Viscosity was investigated as a function of shear rate on a rotational rheometer (MCR 302, AntonPaar, Graz, Austria), and the measurements were performed using a plate/plate measuring setup (PP25). The shear rate was increased from 0.1 to $100 \mathrm{~s}^{-1}$.

The model of Herschel-Bulkley was described by Eqs (2-5):

$$
\sigma=\sigma_{0}+\kappa \times \gamma^{n} \quad(2-5)
$$

where $\sigma(\mathrm{Pa})$ and $\sigma_{0}(\mathrm{~Pa})$ are the shear stress and the yield stress, respectively. $K\left(\mathrm{~Pa} \mathrm{~S}^{\mathrm{n}}\right)$ is the consistency index, $\gamma\left(\mathrm{s}^{-1}\right)$ represents the shear rate, and $n$ represents the flow behavior index.

\section{Oxidative Stability of Emulsions}

The POV was used to measure the primary oxidation products, which was detected using the method of Zhu et al. (20) with slight modification.

As an indicator of the secondary oxidation product, TBARS were evaluated using a previously reported method of Pan et al. (21) with slight modification.

\section{Statistical Analysis}

All experiments were performed in triplicate with parallel samples. All the data were carried out by one-way ANOVA to evaluate significant differences $(p<0.05)$. Origin 9.0 software and SPSS18.0 were used for data analysis.

\section{RESULTS AND DISCUSSION}

\section{Three-Phase Contact Angle}

Pure SPI and BPC initially had the contact angle values of 76.6 and $51.3^{\circ}$, respectively, but the three-phase contact angle of BPC was reduced to $12.7^{\circ}$ when standing for $7.5 \mathrm{~min}$, while there was no obvious change of SPI in the three-phase contact angle. With the SPI/BPC ratio ranging from 4:1 to 2:1, the initial contact angle value of the complexes increased from 61.8 to $71.2^{\circ}$ (Figure 1). This result might be attributed to the presence of the hydroxyl group in BPC, improving the surface hydrophobicity of the complexes by exposing the hidden hydrophobic area in the SPI (22). When the SPI/BPC ratio was 4:3 and 1:1, the contact angle of the complexes decreased to 49.0 and $39.6^{\circ}$, respectively, 


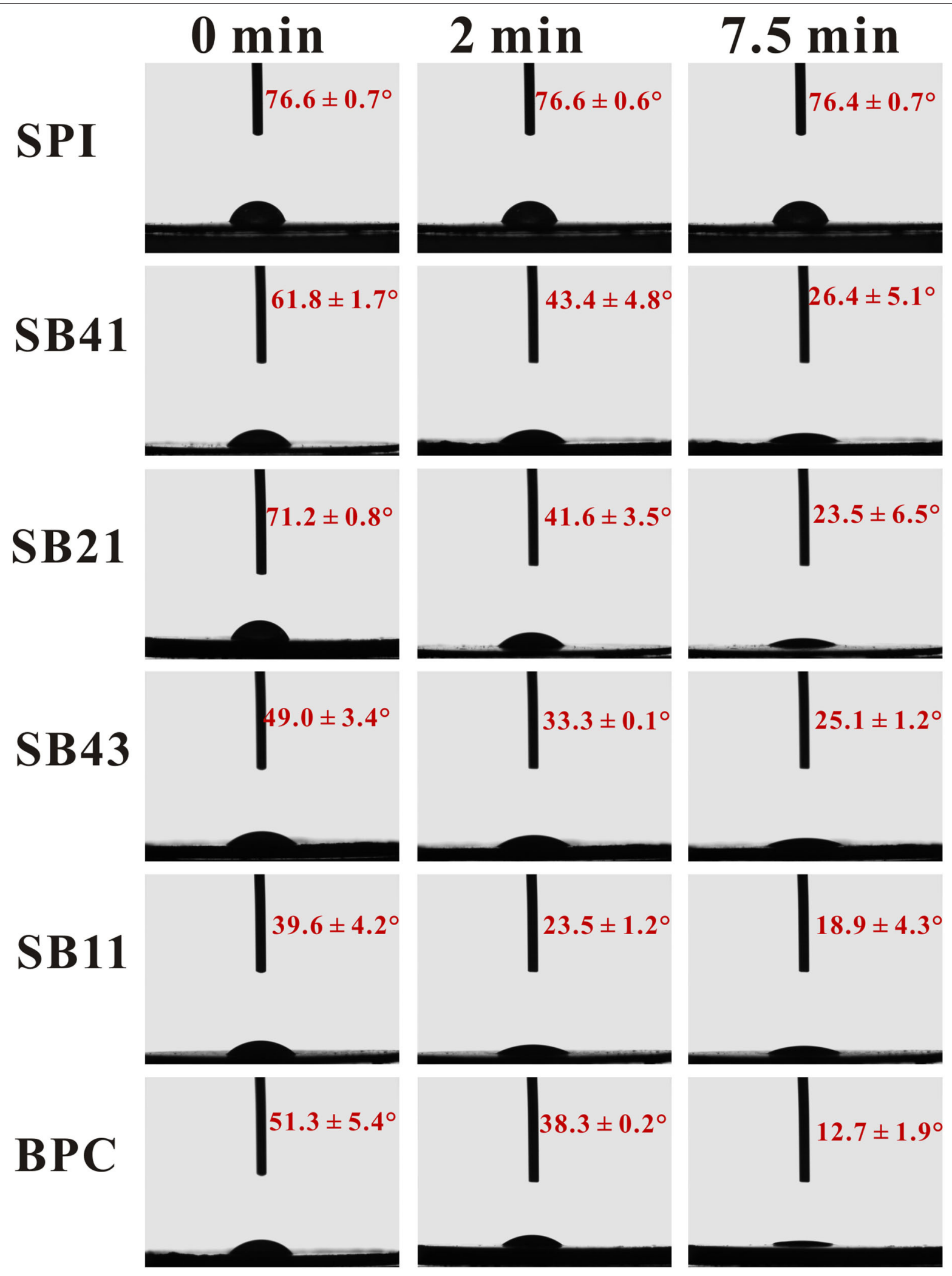

FIGURE 1 | The three-phase contact angle of SPI, BPC, and SPI/BPC colloidal particles with different ratios (4:1, 2:1, 4:3, 1:1). 
A

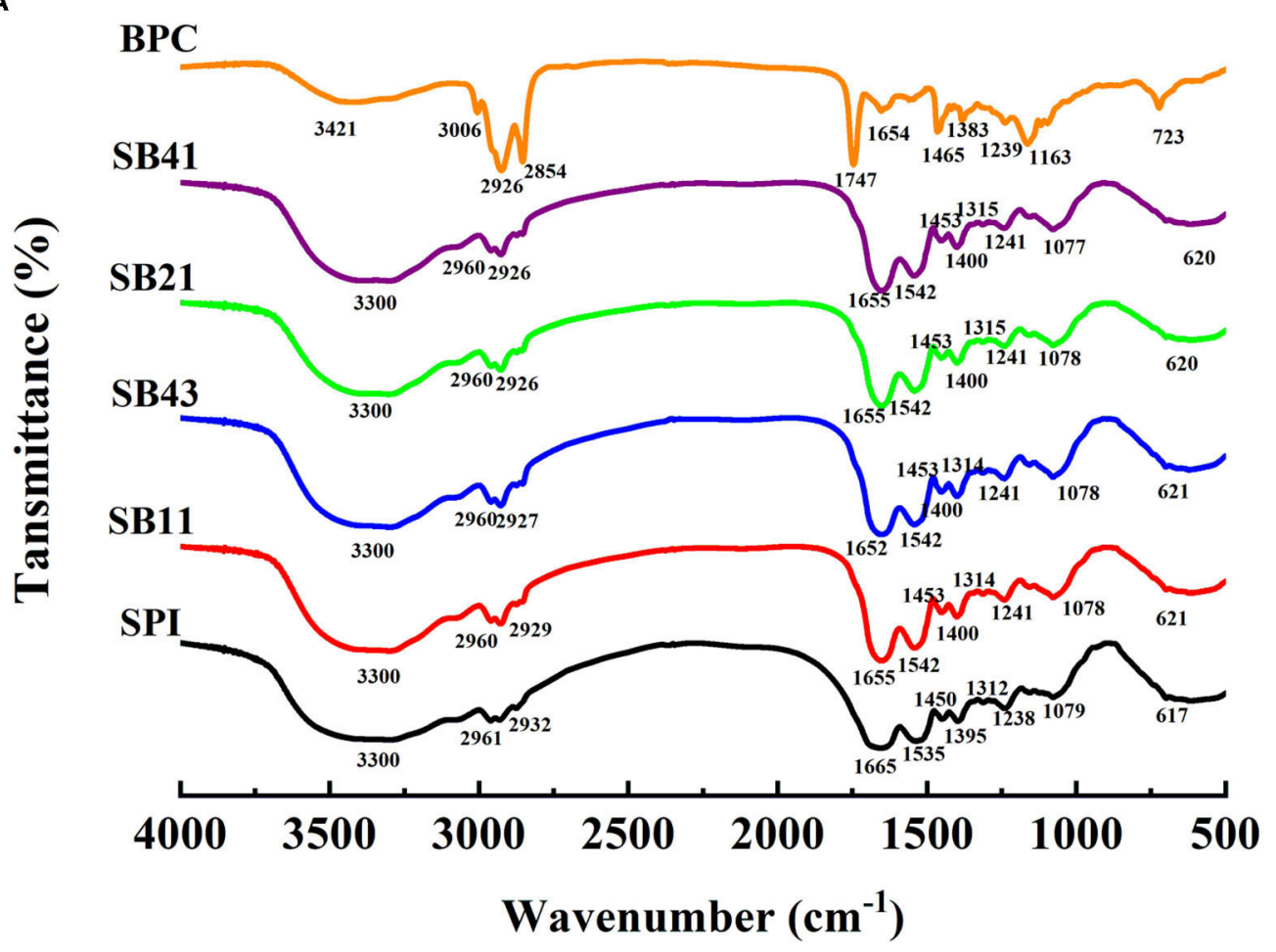

B

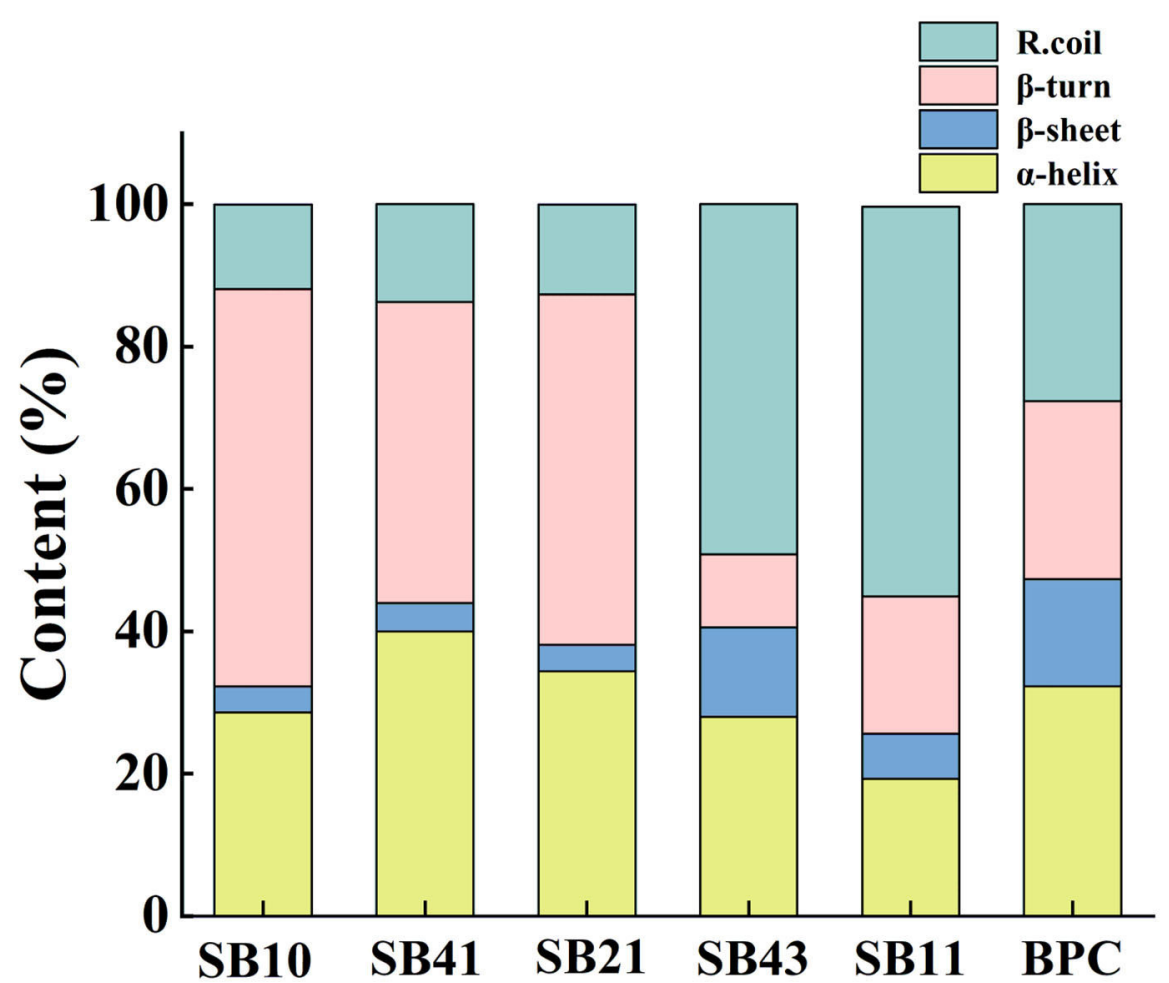

FIGURE 2 | FTIR spectra (A), secondary structure (B) of SPI, BPC, and different SPI/BPC ratios (4:1, 2:1, 4:3, 1:1). 

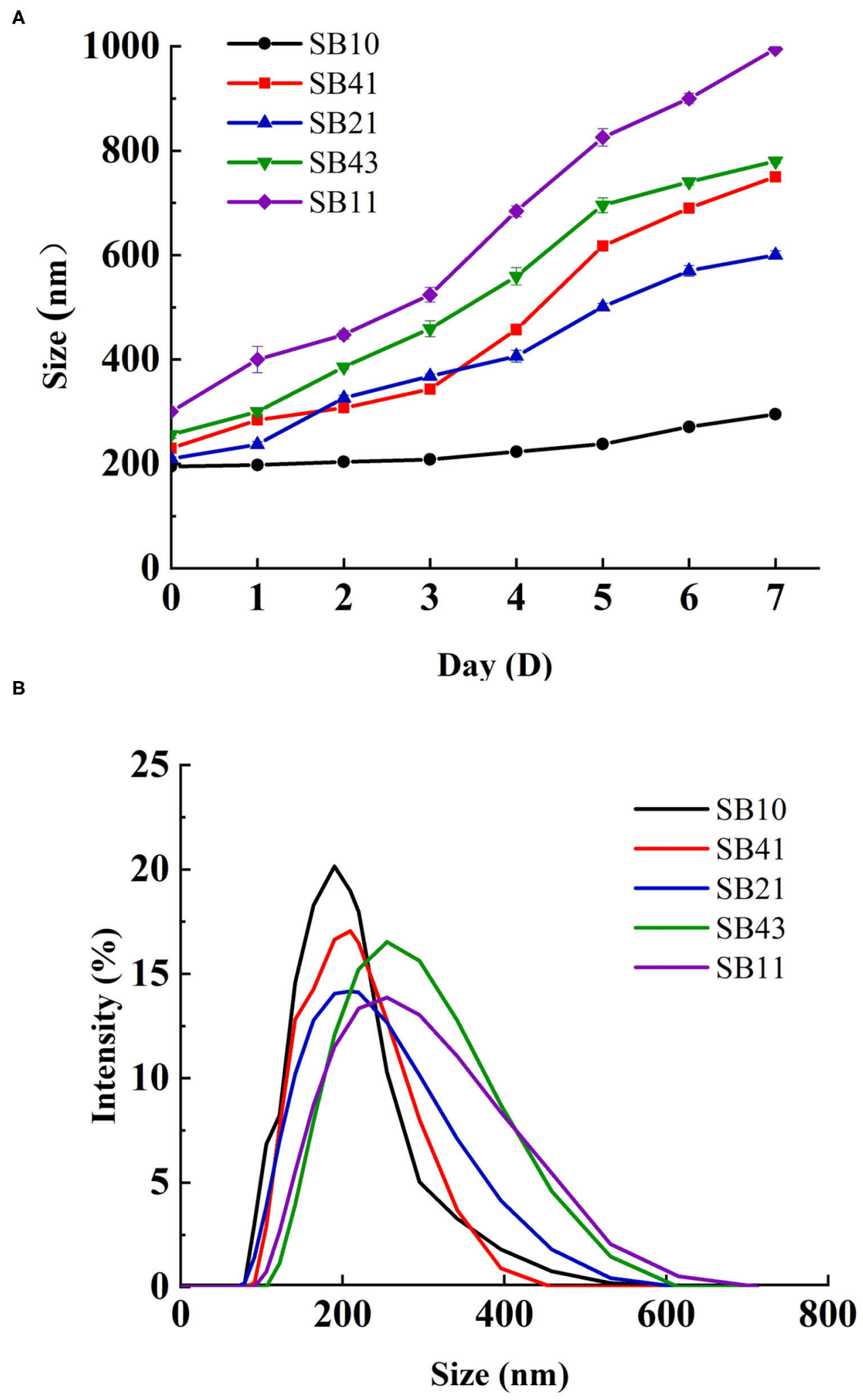

FIGURE 3 | Changes of the emulsions in the average droplet size during storage for 7 days at $25^{\circ} \mathrm{C}$ (A). Droplet size distribution of the emulsions (B). 
probably due to the presence of hydrophilic groups (such as $\mathrm{OH}$ group) carried by excessive BPCs (23). Previous results showed that the use of the particles with intermediate hydrophobicity as a stabilizer could improve the emulsion stability (24). Therefore, the SPI/BPC complex particles at 2:1 might have the best ability to stabilize the emulsions since the contact angle value was the closest to $90^{\circ}$.

\section{FTIR Analysis}

Figure 2A shows the FTIR spectra of SPI and SPI/BPC particles at various mass ratios. There was a broad band over a wavenumber of $3,700-3,200 \mathrm{~cm}^{-1}$, associating with the free stretching vibration of hydroxyl groups in proteins (25). Compared with SPI, the band intensity of SPI/BPC complexes at about 3,300 $\mathrm{cm}^{-1}$ was enhanced, indicating hydrogen bonds formed between SPI and BPC. The peak positioned in the wavenumber range of $2,990-2,850 \mathrm{~cm}^{-1}$ represented the $\mathrm{CH}$ antisymmetric and symmetric stretching of methyl $\left(\mathrm{CH}_{3}\right)$ and methylene $\left(\mathrm{CH}_{2}\right)$ groups that appeared in aliphatic side chain of proteins, and then the peaks (2960 and $2926 \mathrm{~cm}^{-1}$ ) in the spectra were corresponding to the stretching (26). Moreover, the left shift of the C-N stretching and $\mathrm{N}-\mathrm{H}$ bending vibration at 1,542 $\mathrm{cm}^{-1}$ was observed, which might be associated with the electrostatic attraction between the $\mathrm{COO}$ group in SPI and $\mathrm{NH}_{3}^{+}$ group in BPC, thereby promoting the formation of SPI/BPC complexes (27).

As shown in Figure 2B, compared with BPC (45.7\%), the $\beta$ turns and random coil content of SPI/BPC particles from 4:1 to $1: 1$ increased from 63.5 to $71.2 \%$, respectively, reflecting the formation of a more flexible structure that favored the adsorption and unfolding of protein molecules at the oil-water interface and then the enhanced emulsifying properties (13).

\section{Droplet Size}

The mean size of the SPI-stabilized emulsions was about $200 \mathrm{~nm}$ and basically unchanged during 7 days of storage at $25^{\circ} \mathrm{C}$ (Figure 3A). However, the BPC-stabilized emulsions remained stable for only a few hours (data not shown). When the SPI/BPC complex at the mass ratio of 2:1 was employed as a stabilizer, the mean size of emulsion droplets increased from 200 to $595 \mathrm{~nm}$

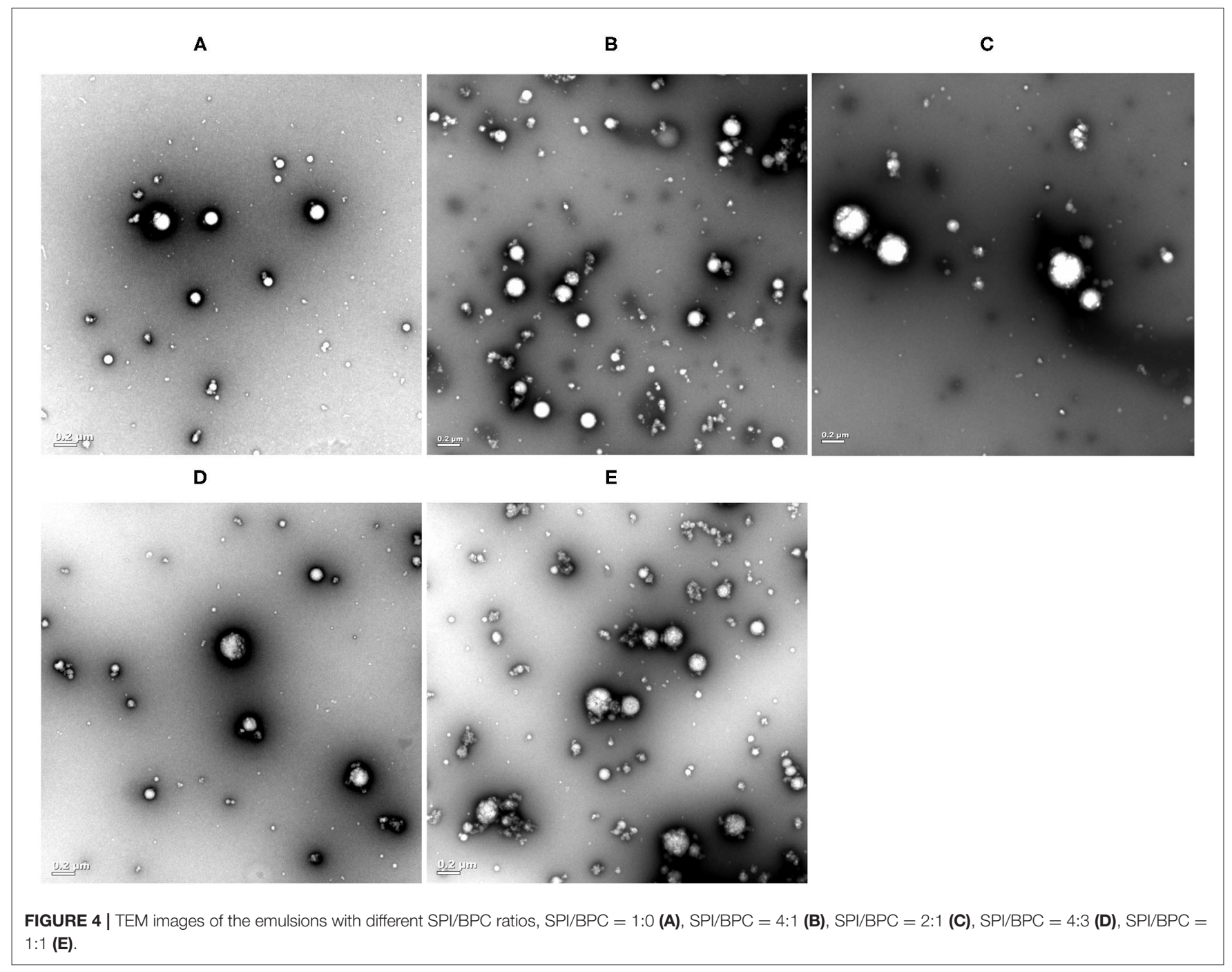


during 7 days storage. As the mass ratio of BPC in the complex further increased, an increasing trend of the emulsions in droplet

TABLE 1 | Zeta potential and interfacial tension of SPI, BPC, and different $\mathrm{SPI} / \mathrm{BPC}$ ratios at various mass ratios.

\begin{tabular}{lccc}
\hline SPI/BPC ratio & Zeta potential $(\mathbf{m V})$ & IFT $(\mathbf{m N} / \mathbf{m})$ & Vol $(\boldsymbol{\mu L})$ \\
\hline $1: 0$ & $-38.13 \pm 0.95^{\mathrm{a}}$ & $50.72 \pm 0.10^{\mathrm{a}}$ & $19.73 \pm 0.23^{\mathrm{a}}$ \\
$4: 1$ & $-26.00 \pm 0.33^{\mathrm{b}}$ & $50.25 \pm 0.05^{\mathrm{b}}$ & $19.09 \pm 0.11^{\mathrm{b}}$ \\
$2: 1$ & $-22.87 \pm 0.29^{\mathrm{c}}$ & $49.91 \pm 0.11^{\mathrm{b}}$ & $18.22 \pm 0.23^{\mathrm{c}}$ \\
$4: 3$ & $-19.33 \pm 0.35^{\mathrm{d}}$ & $49.16 \pm 0.06^{\mathrm{c}}$ & $16.89 \pm 0.08^{\mathrm{d}}$ \\
$1: 1$ & $-20.57 \pm 0.19^{\mathrm{d}}$ & $47.46 \pm 0.14^{\mathrm{d}}$ & $16.56 \pm 0.13^{\mathrm{e}}$
\end{tabular}

Results are expressed as mean values $\pm S D$ of three replicates. Different letters in each column indicate significant difference $(p<0.05)$. size was observed. Especially at the ratio of 1:1, the emulsions were inclined to separate after 7 days. These results indicated that a proper BPC concentration favored the faster adsorption of the complex on the water-in-oil interface, resulting in decreased IFT and then smaller droplet size (28). Moreover, the use of SPI/BPC complex at different ratios as stabilizers did not significantly affect the droplet size distribution of emulsions (Figure 3B), which agreed well with the previous reports of Wang et al. (29).

\section{Zeta Potential Analysis}

The zeta potential of emulsions stabilized by SPI and SPI/BPC are shown in Table 1, and the absolute value of the zeta potential was used for comparison. When the mass ratio of BPC in the complex increased from $4: 1$ to $1: 1$, the zeta potential decreased significantly from -26.00 to $-20.57 \mathrm{mV}$ compared with the pure SPI stabilized emulsion, which was $-38.13 \mathrm{mV}$, and this may
A

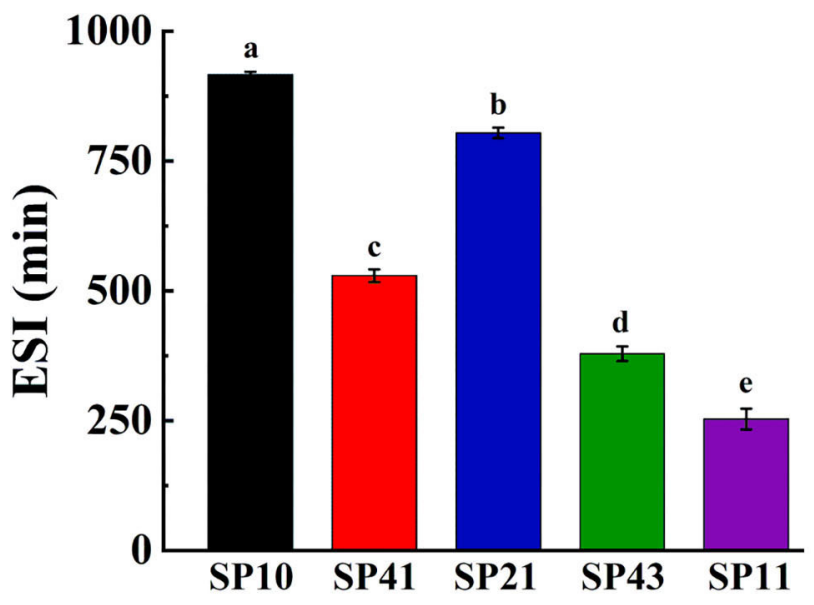

B

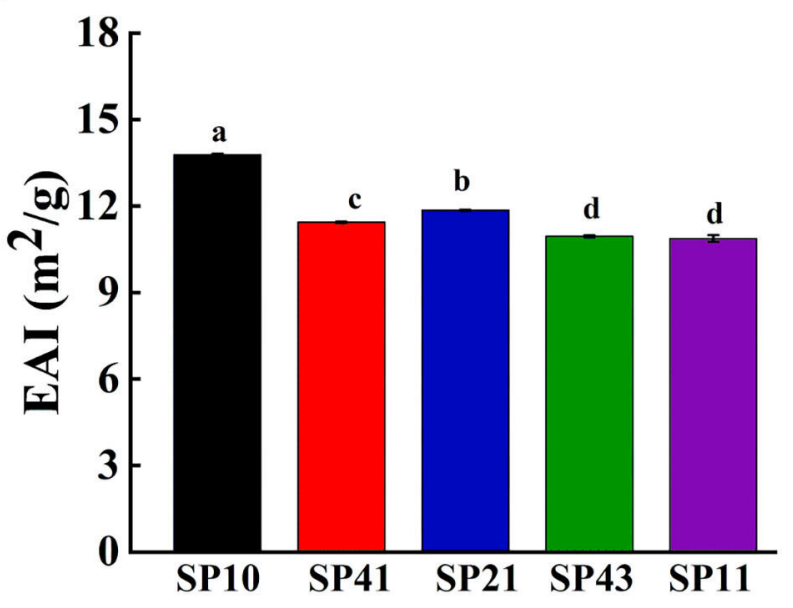

C

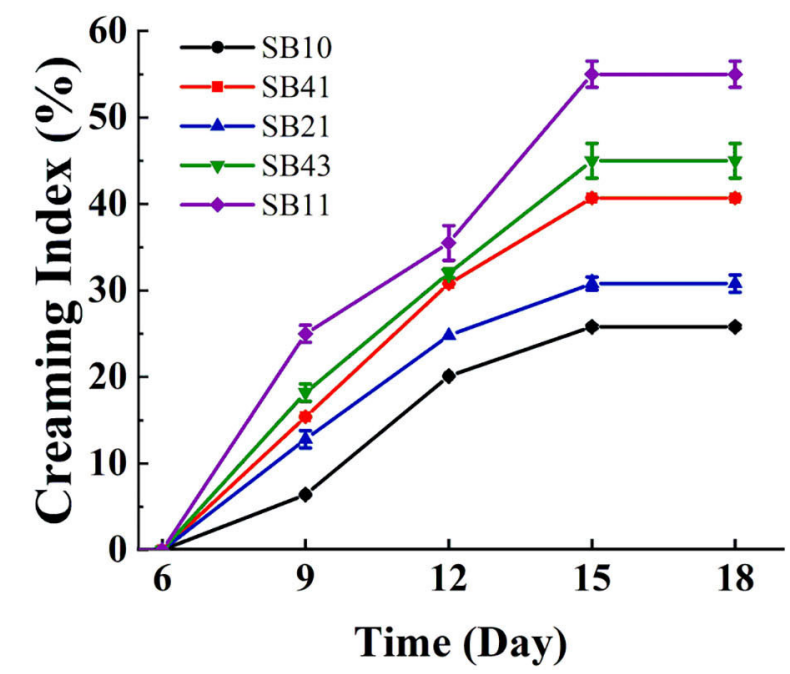

FIGURE 5 | Emulsifying stability index (ESI) (A), emulsion activity index (EAI) (B), creaming index (CI) (C) of SPI, BPC and different SPI/BPC ratios (4:1, 2:1, 4:3, 1:1). 
be attributed to the hydrophobic interactions between SPI and BPC (30). Meanwhile, when the zeta potential decreased, the increase in the size of emulsions may be caused by the decreasing electrostatic repulsion and interfacial strength formed by SPI and $\mathrm{BPC}$ as the ratio of BPC increased (31).

\section{TEM Analysis}

The droplets of the pure SPI-stabilized emulsions possessed spherical shape and uniform size, with a diameter of approximately $200 \mathrm{~nm}$ (Figure 4), in agreement with the result of droplet size measurements. In the previous study, protein attached to the $\mathrm{O} / \mathrm{W}$ interface could lead to a protein network structure (32). With the addition of BPC, the oil droplets were surrounded by SPI/BPC complexes, but the excess
BPC may not absorb the oil-water interface, thus affecting the characteristic of the emulsions.

\section{IFT Analysis}

The interfacial behavior of a stabilizer is considered an important factor influencing emulsion formation and stability. The reduced IFT and the mechanical energy barrier formed at the interface can prevent the emulsion system against coalescence (33). As shown in Table 1, SPI had the highest IFT value of $50.72 \mathrm{mN} / \mathrm{m}$. With the increasing ratio of BPC in the complex, the IFT value of the complex decreased to 50.25 (4:1), 49.91 (2:1), 49.16 (4:3), and $47.46(1: 1) \mathrm{mN} / \mathrm{m}$, respectively. According to Karaca et al. (34), the more soluble proteins favored to reduce IFT because the proteins could shift to the interface. This phenomenon has
A

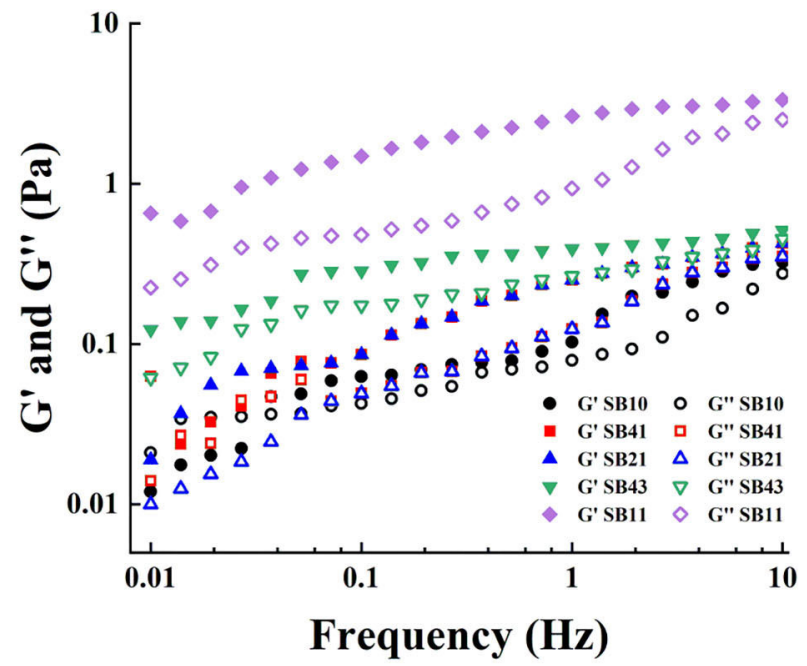

C

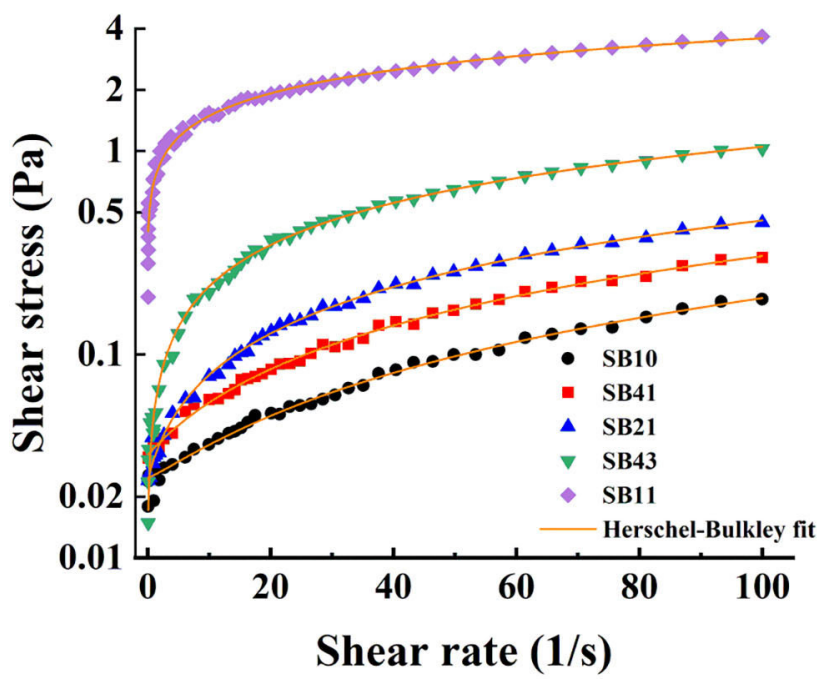

B

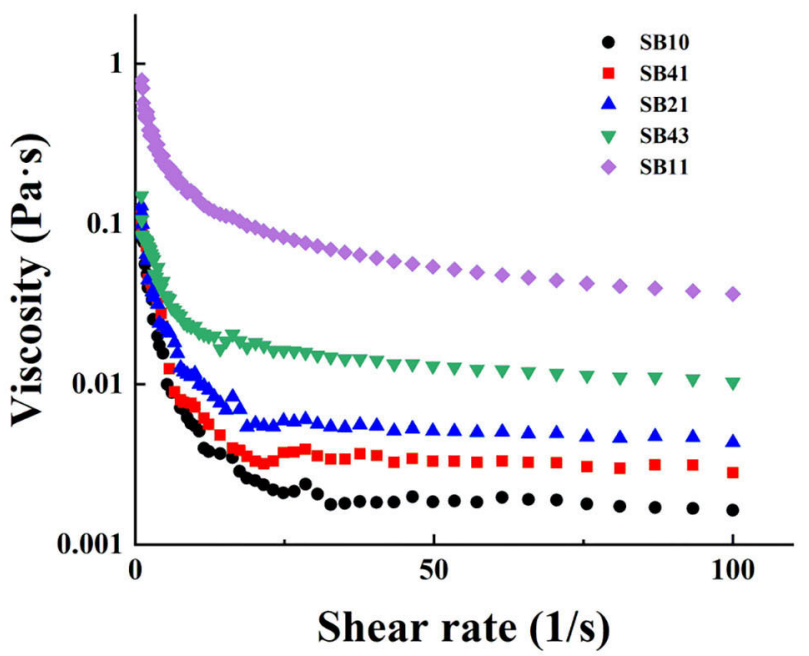


also been proven by Zhang et al. (35), who found that the IFT of all the four samples decreased as the SPI content increased, which helped more SPI molecules get adsorbed on the airwater interface.

\section{Emulsion Stability \\ ESI and EAI}

As shown in Figures $\mathbf{5 A , B}$, the ESI and EAI of the emulsions at different ratios of BPC were significantly affected $(p<$ $0.05)$, respectively. The emulsion stabilized by SPI exhibited the highest ESI $(915.88 \mathrm{~min})$ and EAI $\left(13.79 \mathrm{~g} / \mathrm{m}^{2}\right)$. When the mass ratio of BPC in the complex increased from $4: 1$ to $2: 1$, the ESI and EAI of the emulsions increased from 529.15 to $803.72 \mathrm{~min}$ and from 11.44 to $11.85 \mathrm{~g} / \mathrm{m}^{2}$, respectively, indicating that the addition of BPC could improve the emulsifying activity, and the oil droplets showed better dispersibility at a certain content of BPC (36). However, there was no significant difference in the EAI value between 10.95 and $10.87 \mathrm{~g} / \mathrm{m}^{2}$ at the ratio of $4: 3$ and $1: 1$, indicating that excess BPC was freed from the interface to flocculate via hydrophobic interactions (37).

\section{Cl Analysis}

In general, the $\mathrm{CI}$ and the size variation of the emulsion droplets during storage are used to characterize the emulsion stability (38). Figure 5C shows the curves of CI vs. storage time. No phase separation was observed in the freshly prepared emulsions $(\mathrm{CI} \%=0)$, which was maintained after 7 days of storage, except for the emulsion at the ratio of 1:1. The CI of all the emulsions increased with the increasing time of storage, but the emulsions remained stable until 18 days. As discussed under droplet size, when the SPI/BPC complex at the mass ratio of 2:1 was employed as a stabilizer, the mean emulsion droplet size decreased, resulting in lower creaming indices from 40.7 to $30 \%$, which could be attributed to an insufficient content of stabilizers at the ratio of $4: 1$ to cover the oil droplets (39). The CI of emulsions increased from 30 to $55 \%$ when the ratio of SPI/BPC ranged from $2: 1$ to $1: 1$, which meant the creaming occurred more easily in the emulsions stabilized by the excess BPC and showed poor storage stability (40). Qamar et al. (41) also found a similar result that the CI increased from 5.77 to $8.39 \%$ as the concentration of pea protein increased from 0.5 to $1 \%$, and the emulsion stability against flocculation and coalescence during storage might contribute to the creaming behavior of the pea protein emulsions.

\section{Rheology of Emulsions}

For all the emulsions, the $G^{\prime}$ values were higher than $G^{\prime \prime}$ values at any given frequency (Figure 6A), suggesting the dominant elastic properties of the emulsions (42). Both $G^{\prime}$ and $G^{\prime \prime}$ values of the emulsions at different SPI/BPC ratios increased with the increasing frequency ranging from 0.01 to $10 \mathrm{~Hz}$, indicating that the modulus was frequency-dependent (43). In addition, with the ratio of BPC in the complex increased from $4: 1$ to $1: 1$, the $G^{\prime}$ value was gradually increased to $3.66 \mathrm{~Pa}$, suggesting a progressive enhancement in the gel-like structures (44).

TABLE 2 | Rheological parameters of the emulsions stabilized by SPI/BPC complex using Herschel-Bulkley model.

\begin{tabular}{lllll}
\hline Mass ratios [SPI]: [BPC] & $\boldsymbol{\sigma}_{\mathbf{0}}(\mathbf{P a})$ & $\boldsymbol{K}\left(\mathbf{P a ~ S}^{\mathbf{n}}\right)$ & $\boldsymbol{n}$ & $\boldsymbol{R}^{\mathbf{2}}$ \\
\hline $1: 0$ & 0.0247 & 0.008 & 1.167 & 0.994 \\
$4: 1$ & 0.0320 & 0.002 & 1.022 & 0.997 \\
$2: 1$ & 0.0231 & 0.007 & 0.888 & 0.998 \\
$4: 3$ & 0.0090 & 0.041 & 0.702 & 0.999 \\
$1: 1$ & 0.2232 & 0.478 & 0.424 & 0.996
\end{tabular}
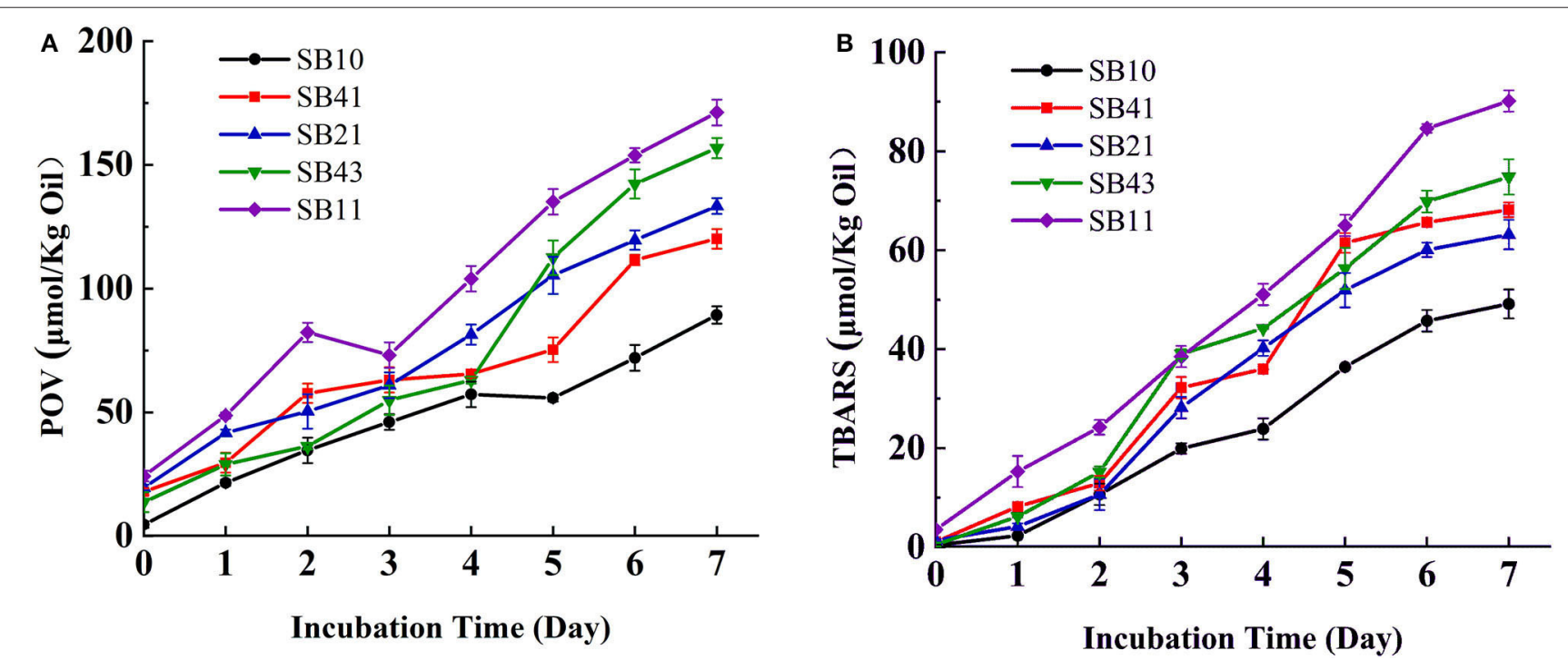

FIGURE 7 | Changes in POV (A) and TBARS (B) of the emulsions with SPI, BPC, and different SPI/BPC ratios (4:1, 2:1, 4:3, 1:1), respectively. 
The apparent viscosity $(\eta)$ of the emulsions stabilized by SPI/BPC complex at various mass ratios gradually decreased with the shear rates increasing from 0.1 to $100 \mathrm{~s}^{-1}$ (Figure 6B), indicating a typical non-Newtonian pseudoplastic behavior. As the ratio of BPC increased from 1:0 to 1:1, the $\eta$ value of the complex stabilized emulsions varied from 0.005 to $0.154 \mathrm{~Pa} \cdot \mathrm{s}$ at a shear rate of $10 \mathrm{~s}^{-1}$, which could lead to enhanced interaction between the droplets (44).

The Herschel-Bulkley model was used to evaluate the flow properties of the emulsions. As shown in Figure 6C, the shear stress vs. shear rate data at all the mass ratios showed a good correlation with Herschel-Bulkley models $\left(R^{2}>0.99\right)$. The $K$ value increasing with the increased ratio of BPC in the complex reflecting the change in the viscosity of emulsion and the shear-thinning behavior of the emulsions as a nonNewtonian fluid. (45). Furthermore, the $n$ values of all emulsion were $<1$ (Table 2), which confirmed the pseudoplastic fluid characteristics. The increased ratio of BPC in the emulsions decreased the $n$ value, suggesting that the deviation from Newtonian behavior gradually increased (46).

\section{Oxidation Stability of Emulsions}

Figure 7 shows the changes in POV and TBARS of the emulsions as a function of storage time at $25^{\circ} \mathrm{C}$. POV indicates the levels of hydroperoxides formed from fatty acid radicals during oxidation processes, while TBARS shows the content of malondialdehyde that is a secondary lipid oxidation product from polyunsaturated fatty acids (47). After 7 days of storage, the POV value of the emulsions stabilized by the SPI/BPC complex at the mass ratio of $1: 1$ increased remarkably from almost zero to $171 \mu \mathrm{mol} / \mathrm{kg}$ oil, revealing the occurrence of lipid oxidation in the emulsions during storage. In addition, the POVs of emulsions increased from 89.3 to $171 \mu \mathrm{mol} / \mathrm{kg}$ oil with the ratio of SPI/BPC increasing from $4: 1$ to $1: 1$. The changes in TBARS contents had a similar trend to those of POVs, indicating that the primary oxidation products might be transformed into secondary oxidation products (48). Generally, emulsion system trended to be oxidized due to the existence of an oil-water interface, and some unabsorbed molecules could affect the lipid oxidation process like the excess BPC content in the ratio of 1:1 (49).

\section{REFERENCES}

1. Silva MF, Menis-Henrique ME, Felisberto MH, Goldbeck R, Clerici MT. Bamboo as an eco-friendly material for food and biotechnology industries. Curr Opin Food Sci. (2020) 33:124-30. doi: 10.1016/j.cofs.2020.02.008

2. Wang Y, Chen J, Wang D, Ye F, He Y, Hu Z, et al. A systematic review on the composition, storage, processing of bamboo shoots: focusing the nutritional and functional benefits. J Funct Foods. (2020) 71:104015. doi: 10.1016/j.jff.2020.104015

3. Sayanika DW, Louis B, Pranab R, Narayan CT. Insights on predominant edible bamboo shoot proteins. Afr J Biotechnol. (2015) 14:1511-8. doi: 10.5897/AJB2015.14425

4. Wang $\mathrm{H}, \mathrm{Ng} \mathrm{T}$. Dendrocin, a distinctive antifungal protein from bamboo shoots. Biochem Biophys Res Commun. (2003) 307:750-5. doi: 10.1016/S0006-291X(03)01229-4

5. Liu L, Liu L, Lu B, Xia D, Zhang Y. Evaluation of antihypertensive and antihyperlipidemic effects of bamboo shoot angiotensin converting

\section{CONCLUSIONS}

In this study, the camellia $\mathrm{O} / \mathrm{W}$ emulsions were prepared with the SPI/BPC complex as a new stabilizer. The hydrogen bonding and electrostatic attractions dominated the binding of BPC to SPI, which could improve the surface hydrophobicity and induce a network layer structure of the SPI/BPC complex at the mass ratio of 2:1. When the complex was used to stabilize the emulsions, the increasing ratio of BPC increased the droplet size but decreased the IFT. The emulsions had a shear-thinning and dominant elastic behavior, and the emulsions stabilized by the complex at the ratio of 2:1 showed better storage and antioxidant stability. This work showed the great potential of BPC as a new additive to the emulsion-based food products.

\section{DATA AVAILABILITY STATEMENT}

The raw data supporting the conclusions of this article will be made available by the authors, without undue reservation.

\section{AUTHOR CONTRIBUTIONS}

YX: conceptualization, methodology, investigation, data curation, and writing-original draft preparation. AZ: formal analysis and software. $\mathrm{ZW:}$ resources and investigation. SF: formal analysis and data curation. CZ: methodology, data curation, and supervision. LW: validation and visualization. HZ: project administration, visualization, conceptualization, review and editing, and funding acquisition. All authors contributed to the article and approved the submitted version.

\section{FUNDING}

This study was financially supported by the Zhejiang Provincial Natural Science Foundation of China for Distinguished Young Scholars (Grant No. LR20C200001), and the Zhejiang Provincial Natural Science Foundation of China (Grant No. $2020 \mathrm{C02036}$ and 2021C02032). enzyme inhibitory peptide in vivo. J Agric Food Chem. (2012) 60:11351-8. doi: 10.1021/jf303471f

6. Nishinari K, Fang Y, Guo S, Phillips G. Soy proteins: A review on composition, aggregation and emulsification. Food Hydrocoll. (2014) 39:30118. doi: 10.1016/j.foodhyd.2014.01.013

7. Liu F, Tang $\mathrm{C}-\mathrm{H}$. Soy protein nanoparticle aggregates as pickering stabilizers for oil-in-water emulsions. J Agric Food Chem. (2013) 61:8888-98. doi: 10.1021/jf401859y

8. Benetti JVM. do Prado Silva JT, Nicoletti VR. SPI microgels applied to Pickering stabilization of $\mathrm{O} / \mathrm{W}$ emulsions by ultrasound and high-pressure homogenization: rheology and spray drying. Food Res Int. (2019) 122:383-91. doi: 10.1016/j.foodres.2019.04.020

9. Vasconcellos F, Woiciechowski A, Soccol V, Mantovani D, Soccol C. Antimicrobial and antioxidant properties of conglycinin and glycinin from soy protein isolate. Int J Curr Microbiol Appl Sci. (2014) 3:144-57.

10. Wei Z, Cheng Y, Huang Q. Heteroprotein complex formation of ovotransferrin and lysozyme: fabrication of food-grade particles to 
stabilize Pickering emulsions. Food Hydrocoll. (2019) 96:190-200. doi: 10.1016/j.foodhyd.2019.05.024

11. Zhang X, Zhang S, Xie F, Han L, Li L, Jiang L, et al. Soy/whey protein isolates: interfacial properties and effects on the stability of oilin-water emulsions. J Sci Food Agric. (2021) 101:262-71. doi: 10.1002/jsfa. 10638

12. Aderinola TA, Alashi AM, Nwachukwu ID, Fagbemi TN, Enujiugha VN, Aluko RE. In vitro digestibility, structural and functional properties of moringa oleifera seed proteins. Food Hydrocoll. (2020) 101:105574. doi: 10.1016/j.foodhyd.2019.105574

13. Yu J, Wang G, Wang $\mathrm{X}, \mathrm{Xu} \mathrm{Y}$, Chen $\mathrm{S}$, Wang $\mathrm{X}$, et al. Improving the freeze-thaw stability of soy protein emulsions via combing limited hydrolysis and maillard-induced glycation. LWT Food Sci Technol. (2018) 91:63-9. doi: 10.1016/j.lwt.2018.01.031

14. Chantrapornchai W, Clydesdale F, McClements DJ. Influence of droplet size and concentration on the color of oil-in-water emulsions. J Agric Food Chem. (1998) 46:2914-20. doi: 10.1021/jf980278z

15. Verma K, Tarafdar A, Mishra V, Dilbaghi N, Kondepudi KK, Badgujar PC. Nanoencapsulated curcumin emulsion utilizing milk cream as a potential vehicle by microfluidization: bioaccessibility, cytotoxicity and physico-functional properties. Food Res Int. (2021) 148:110611. doi: 10.1016/j.foodres.2021.110611

16. Chen X, Sun S, Ma C, Yang X. Oil-water interfacial-directed spontaneous self-assembly of natural quillaja saponin for controlling interface permeability in colloidal emulsions. J Agric Food Chem. (2020) 68:13854-62. doi: 10.1021/acs.jafc.0c04431

17. Pearce KN, Kinsella JE. Emulsifying properties of proteins: evaluation of a turbidimetric technique. J Agric Food Chem. (1978) 26:716-23. doi: $10.1021 / \mathrm{j} f 60217 \mathrm{a} 041$

18. Chen J, Zhang X, Xue S, Xu X. Effects of ultrasound frequency mode on myofibrillar protein structure and emulsifying properties. Int J Biol Macromol. (2020) 163:1768-79. doi: 10.1016/j.ijbiomac.2020.09.114

19. Iqbal S, Chen XD, Kirk TV, Huang H. Controlling the rheological properties of W1/O/W2 multiple emulsions using osmotic swelling: impact of WPI-pectin gelation in the internal and external aqueous phases. Colloids Surf, B. (2020) 185:110629. doi: 10.1016/j.colsurfb.2019.110629

20. Zhu Y, Fu S, Wu C, Qi B, Teng F, Wang Z, et al. The investigation of protein flexibility of various soybean cultivars in relation to physicochemical and conformational properties. Food Hydrocoll. (2020) 103:105709. doi: 10.1016/j.foodhyd.2020.105709

21. Pan J, Tang L, Dong Q, Li Y, Zhang H. Effect of oleogelation on physical properties and oxidative stability of camellia oil-based oleogels and oleogel emulsions. Food Res Int. (2021) 140:110057. doi: 10.1016/j.foodres.2020.110057

22. Wang L-J, Hu Y-Q, Yin S-W, Yang X-Q, Lai F-R, Wang S-Q. Fabrication and characterization of antioxidant pickering emulsions stabilized by zein/chitosan complex particles (ZCPs). J Agric Food Chem. (2015) 63:251424. doi: 10.1021/jf505227a

23. Liu Z, Lin D, Shen R, Yang X. Bacterial cellulose nanofibers improved the emulsifying capacity of soy protein isolate as a stabilizer for pickering high internal-phase emulsions. Food Hydrocoll. (2021) 112:106279. doi: 10.1016/j.foodhyd.2020.106279

24. Tsabet E, Fradette L. Study of the properties of oil, particles, and water on particle adsorption dynamics at an oil/water interface using the colloidal probe technique. Chem Eng Res Des. (2016) 109:307-16. doi: 10.1016/j.cherd.2016.02.001

25. Wang $\mathrm{Y}$, Zhang A, Wang $\mathrm{X}, \mathrm{Xu} \mathrm{N}$, Jiang L. The radiation assistedmaillard reaction comprehensively improves the freeze-thaw stability of soy protein-stabilized oil-in-water emulsions. Food Hydrocoll. (2020) 103:105684. doi: 10.1016/j.foodhyd.2020.105684

26. Tan E-S, Ying-Yuan N, Gan C-Y. A comparative study of physicochemical characteristics and functionalities of pinto bean protein isolate (PBPI) against the soybean protein isolate (SPI) after the extraction optimisation. Food Chem. (2014) 152:447-55. doi: 10.1016/j.foodchem.2013.12.008

27. Niu F, Niu D, Zhang H, Chang C, Gu L, Su Y, et al. Ovalbumin/gum arabic-stabilized emulsion: rheology, emulsion characteristics, and raman spectroscopic study. Food Hydrocoll. (2016) 52:607-14. doi: $10.1016 /$ j.foodhyd.2015.08.010
28. Khan A, Iram B, Seemab P, Khalid M, Mohammad S, Mohammad S. Surface tension, density and viscosity studies on the associative behaviour of oxyethylene-oxybutylene diblock copolymers in water at different temperatures. Int J Org Chem. (2012) 2:82-92. doi: 10.4236/ijoc.2012.21014

29. Wang Y, Li D, Wang L, Adhikari B. The effect of addition of flaxseed gum on the emulsion properties of soybean protein isolate (SPI). J Food Eng. (2011) 104:56-62. doi: 10.1016/j.jfoodeng.2010.11.027

30. Liu Y, Wei Z-C, Deng Y-Y, Dong H, Zhang Y, Tang X-J, et al. Comparison of the effects of different food-grade emulsifiers on the properties and stability of a casein-maltodextrin-soybean oil compound emulsion. Molecules. (2020) 25:458. doi: 10.3390/molecules 25030458

31. Wang S, Yang J, Shao G, Qu D, Zhao H, Yang L, et al. Soy protein isolatedsoy hull polysaccharides stabilized $\mathrm{O} / \mathrm{W}$ emulsion: effect of polysaccharides concentration on the storage stability and interfacial rheological properties. Food Hydrocoll. (2020) 101:105490. doi: 10.1016/j.foodhyd.2019.105490

32. Li Y, Liu H, Liu Q, Kong B, Diao X. Effects of zein hydrolysates coupled with sage (salvia officinalis) extract on the emulsifying and oxidative stability of myofibrillar protein prepared oil-in-water emulsions. Food Hydrocoll. (2019) 87:149-57. doi: 10.1016/j.foodhyd.2018.07.052

33. Wang M, Chen X, Guo J, Yang J, Wang J, Yang X. Stabilization of foam and emulsion by subcritical water-treated soy protein: effect of aggregation state. Food Hydrocoll. (2019) 87:619-28. doi: 10.1016/j.foodhyd.2018.08.047

34. Karaca AC, Low N, Nickerson M. Emulsifying properties of chickpea, faba bean, lentil and pea proteins produced by isoelectric precipitation and salt extraction. Food Res Int. (2011) 44:2742-50. doi: 10.1016/j.foodres.2011.06.012

35. Zhang A, Cui Q, Yu Z, Wang X, Zhao X. Effects of transglutaminase glycosylated soy protein isolate on its structure and interfacial properties. $J$ Sci Food Agric. (2021) 101:5097-105. doi: 10.1002/jsfa.11155

36. Pirestani S, Nasirpour A, Keramat J, Desobry S, Jasniewski J. Effect of glycosylation with gum Arabic by maillard reaction in a liquid system on the emulsifying properties of canola protein isolate. Carbohydr Polym. (2017) 157:1620-7. doi: 10.1016/j.carbpol.2016.11.044

37. Liu H, Li Y, Diao X, Kong B, Liu Q. Effect of porcine bone protein hydrolysates on the emulsifying and oxidative stability of oil-in-water emulsions. Colloids Surf A. (2018) 538:757-64. doi: 10.1016/j.colsurfa.2017.11.061

38. Sharkawy A, Barreiro MF, Rodrigues AE. New Pickering emulsions stabilized with chitosan/collagen peptides nanoparticles: synthesis, characterization and tracking of the nanoparticles after skin application. Colloids Surf A. (2021) 616:126327. doi: 10.1016/j.colsurfa.2021.126327

39. Can Karaca A, Nickerson MT, Low NH. Lentil and chickpea protein-stabilized emulsions: optimization of emulsion formulation. J Agric Food Chem. (2011) 59:13203-11. doi: 10.1021/jf203028n

40. Liu N, Li N, Faiza M, Li D, Yao X, Zhao M. Stability and in vitro digestion of high purity diacylglycerol oil-in-water emulsions. LWT Food Sci Technol. (2021) 148:111744. doi: 10.1016/j.lwt.2021.111744

41. Qamar S, Bhandari B, Prakash S. Effect of different homogenisation methods and UHT processing on the stability of pea protein emulsion. Food Res Int. (2019) 116:1374-85. doi: 10.1016/j.foodres.2018.10.028

42. Feng T, Wang X, Wang X, Zhang X, Gu Y, Xia S, et al. High internal phase pickering emulsions stabilized by pea protein isolate-high methoxyl pectinEGCG complex: interfacial properties and microstructure. Food Chem. (2021) 350:129251. doi: 10.1016/j.foodchem.2021.129251

43. Wei Y, Xie Y, Cai Z, Guo Y, Zhang H. Interfacial rheology, emulsifying property and emulsion stability of glyceryl monooleate-modified corn fiber gum. Food Chem. (2021) 343:128416. doi: 10.1016/j.foodchem.2020.1 28416

44. Lv P, Wang D, Dai L, Wu X, Gao Y, Yuan F. Pickering emulsion gels stabilized by high hydrostatic pressure-induced whey protein isolate gel particles: characterization and encapsulation of curcumin. Food Res Int. (2020) 132:109032. doi: 10.1016/j.foodres.2020.109032

45. Katsaros G, Tsoukala M, Giannoglou M, Taoukis P. Effect of storage on the rheological and viscoelastic properties of mayonnaise emulsions of different oil droplet size. Heliyon. (2020) 6:e05788. doi: 10.1016/j.heliyon.2020.e05788

46. Zhang $\mathrm{C}$, Li Y, Wang P, Zhang A, Feng F, Zhang H. Electrospinning of bilayer emulsions: the role of gum Arabic as a coating layer in the gelatin-stabilized emulsions. Food Hydrocoll. (2019) 94:38-47. doi: 10.1016/j.foodhyd.2019.03.013 
47. Zha F, Dong S, Rao J, Chen B. Pea protein isolate-gum Arabic Maillard conjugates improves physical and oxidative stability of oil-in-water emulsions. Food Chem. (2019) 285:130-8. doi: 10.1016/j.foodchem.2019.01.151

48. Wang LL, Xiong YL. Inhibition of lipid oxidation in cooked beef patties by hydrolyzed potato protein is related to its reducing and radical scavenging ability. J Agric Food Chem. (2005) 53:9186-92. doi: 10.1021/jf051213g

49. Nasrabadi MN, Doost AS, Goli SAH, Van der Meeren P. Effect of thymol and pickering stabilization on in-vitro digestion fate and oxidation stability of plant-derived flaxseed oil emulsions. Food Chem. (2020) 311:125872. doi: 10.1016/j.foodchem.2019.125872

Conflict of Interest: The authors declare that the research was conducted in the absence of any commercial or financial relationships that could be construed as a potential conflict of interest.
Publisher's Note: All claims expressed in this article are solely those of the authors and do not necessarily represent those of their affiliated organizations, or those of the publisher, the editors and the reviewers. Any product that may be evaluated in this article, or claim that may be made by its manufacturer, is not guaranteed or endorsed by the publisher.

Copyright (๑) 2021 Xi, Zhang, Wang, Farooq, Zhang, Wu and Zhang. This is an open-access article distributed under the terms of the Creative Commons Attribution License (CC BY). The use, distribution or reproduction in other forums is permitted, provided the original author(s) and the copyright owner(s) are credited and that the original publication in this journal is cited, in accordance with accepted academic practice. No use, distribution or reproduction is permitted which does not comply with these terms. 